Research Paper

\title{
The Cause and Prevention of Anastomotic Recurrence following Colectomy: An Immunohistochemical Approach for Detecting Transforming Colonocytes
}

\author{
M. Arlen $133^{\bowtie}$, J. Crawford ${ }^{2}$, G. Coppa ${ }^{1}$, O. Saric ${ }^{3}$, J. Bandovic ${ }^{2}$, A. Doubakovski³, J. Sullivan ${ }^{1}$, C. Conte ${ }^{1}$, \\ A. Kadison ${ }^{1}$, J. Procaccino ${ }^{1}$, P. Arlen ${ }^{3}$, X. Wang 3 , E. Molmenti ${ }^{1}$ \\ 1. Dept. Surgery NSUH, Manhasset NY, USA; \\ 2. Dept. Pathology NSUH, Manhasset NY, USA; \\ 3. Dept. Precision Biologics, Great Neck NY, USA. \\ $\triangle$ Corresponding author: Myron Arlen, MD, myronarlen@yahoo.com. \\ (C) Ivyspring International Publisher. This is an open-access article distributed under the terms of the Creative Commons License (http://creativecommons.org/ \\ licenses/by-nc-nd/3.0/). Reproduction is permitted for personal, noncommercial use, provided that the article is in whole, unmodified, and properly cited.
}

Received: 2014.04.23; Accepted: 2014.06.18; Published: 2014.10.23

\begin{abstract}
With the ability to identify the presence of transforming colonocytes in a field adjacent to an existing primary colon cancer, it is now possible to reduce if not eliminate one of the major causes leading to anastomotic tumor recurrence. In a review of those colectomy cases that presented post-surgery with anastomotic recurrence, we noted that mucosal abnormalities could readily be detected adjacent to the primary lesion. Such changes had gone unrecognized at the time of surgery, when standard histologic procedures were employed. By utilizing monoclonal antibodies (mAbs) that defined the presence of tumor immunogenic proteins, we were able to reexamine so-called normal biopsy sites adjacent to the tumor. Here, it was possible to demonstrate the presence of altered cellular activity in existing phenotypically normal appearing colonocytes that were in the process of transforming to malignancy.

Eight consecutive patients that had been admitted for evaluation and resection of an anastomotic recurrence post colectomy, were studied with regard to possible etiologic factors. The original margins incorporated into the anastomosis were re-examined by immunohistochemistry employing those monoclonal antibodies (mAbs) designed to target colon tumor antigen. This antigen had previously been shown to be expressed only in colon cancer and not in adjacent normal tissue. In addition, biopsies from margins of resection in five patients free of recurrence following colectomy were also studied along with colon specimens from 50 normal patients, non-demonstrating expression of tumor antigen in the normal appearing colonocytes.

In each of the patients who had presented with anastomotic recurrence, normal appearing colonocytes defined by light microscopy and found adjacent to the previously resected primary lesion, expressed tumor antigen. The antigen detected in these colonocytes proved to be identical to antigen expressed in the anastomotic recurrence giving credence to the concept that these normal appearing cells in proximity to the tumor were responsible for the regrowth of tumor in the suture line used to establish continuity of the bowel.

Based on the findings of this preliminary retrospective study it is felt that at the time of performing a colectomy for a malignant lesion of the bowel, that it is important that those normal appearing colonocytes adjacent to tumor be evaluated for expression of tumor associated antigen. Excluding such cells from an anastomosis, may help to assure that tumor recurrence will be minimized if not totally eliminated.
\end{abstract}

Key words: Anastomotic recurrence, immunohistochemistry, monoclonal antibodies, colon tumor antigen. 


\section{Introduction}

In a small, but well defined number of cases, development of an anastomotic recurrence following colectomy for a malignant lesion will occur. (1). The figures for the incidence of such recurrence have ranged from $10-15 \%$ of those patients so treated. Unfortunately when an anastomotic recurrence is noted within the one to two year period following surgery, end results following re-resection are usually poor. It is also felt that when the margin of resection that can be obtained surgically is suboptimal when there is proximity to the levator ani sphincter at the time of low anterior resection, that the incidence of recurrence is more frequently noted. Speculations as to possible causes for this complication have been numerous $(2$, 3). Various surgical modifications have as such been introduced, but most have failed to reduce the overall incidence of this complication (4). Based on these results, improved technical issues related to performance of this procedure have been found to be of little or no consequence in reducing this problem (5). Recurrence of tumor in this situation, after investigation of a number of possible issues, now appears to be the result of a failure to define premalignant changes noted histologically in the mucosal field adjacent to the primary lesion. Such cellular changes in normal appearing colonocytes within proximity of the primary bowel lesion take place on a molecular level within the normal appearing colonocytes. These transforming cells may inadvertently be incorporated into the suture line used for establishing bowel continuity and be the root cause of the anastomotic recurrence (6).

\section{H\&E of normal adacent to colon ca case \#2}
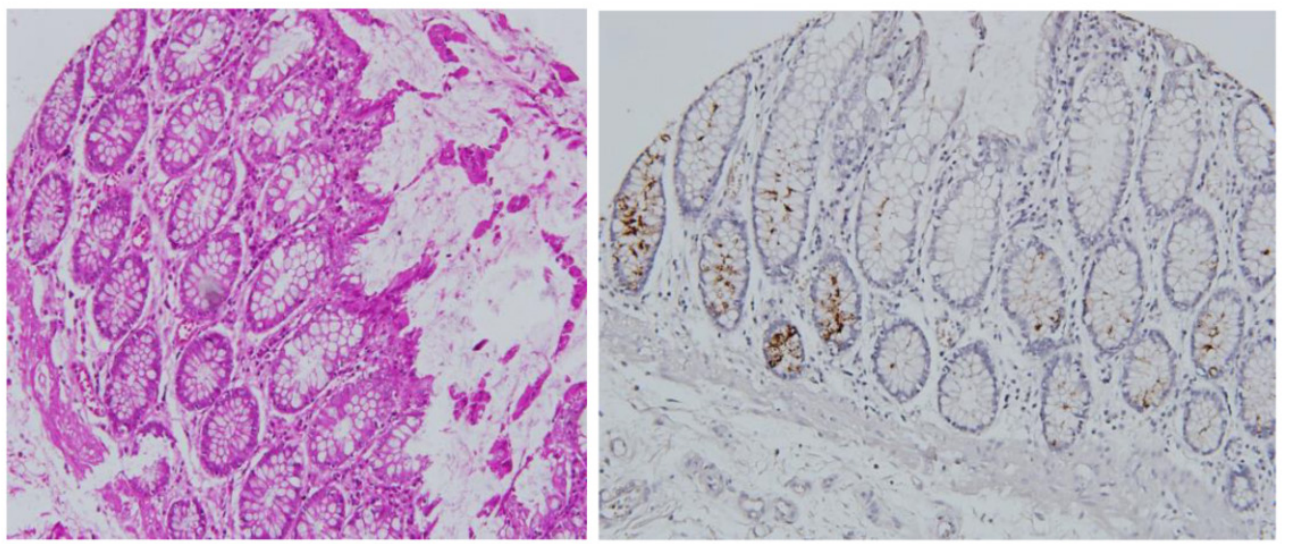

Figure 1. A demonstrates normal appearing colonocytes at the margins of resection, stained by H\&E. B shows the appearance of these same cells evaluated by immuno-histochemical staining with one of the tumor monoclonal antibodies, 31.1, derived from colon tumor associated antigen (TAA). Tumor antigen is clearly noted to be expressed in many of the cells. 


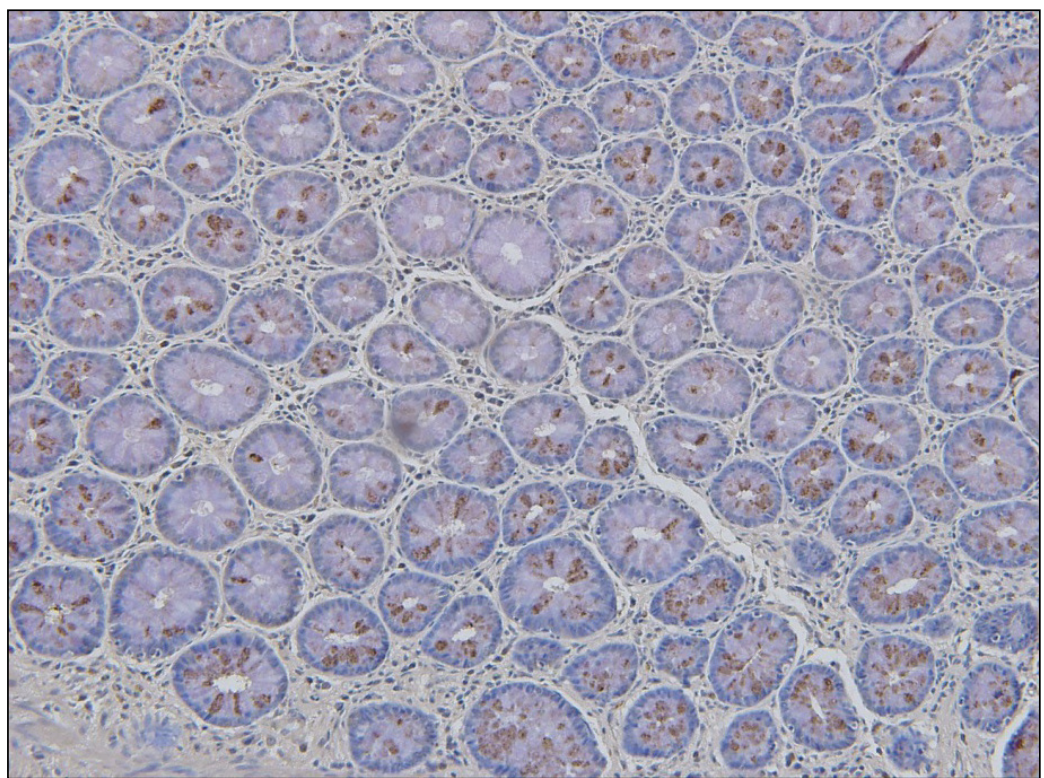

Figure 2. Illustrates the expression of tumor antigen (brown nodular pigment) defined by monoclonal Neo 201 in normal colonocytes examined at the margin of resection in a patient presenting with recurrence anastomotic tumor.

Monoclonal antibodies (MAbs) used to examine colon margins adjacent to the resected primary tumor, were initially developed as hybridomas by our group. They were then sequenced and transfected into $\mathrm{CHO}$ cells to allow for stability of the mAbs. These mAbs were capable of identifying and characterizing the immunogenic glycoproteins expressed in essentially all colon adenocarcinomas examined, and now for the first time in normal appearing colonocytes adjacent to the primary bowel lesion. (8) (Fig. 2)

Tumor antigens (TAA's) present in colon cancers, had first been isolated from pooled allogeneic membrane homogenates obtained from operating room specimens.(10) These tumor proteins, were fractionated and tested for specificity by delayed cutaneous hypersensitivity in individuals with colorectal cancer as well as healthy volunteers. The mAbs that were developed from colon TAA were later utilized for immunoprecipitation of partially purified antigen extracts. Further characterization was achieved by mass spectroscopy. Three distinct oncofetal proteins were identified. They were found to be expressed alone, and in various combinations within the tumors examined. The antibodies found targeting the colon tumor proteins not only served to define effective tumor markers by immunohistochemistry (IHC) and thru serum ELISA, but could also target the tumor for destruction thru antibody dependent cell cytotoxicity (ADCC) when the correct protein was present. (11)

The oncofetal proteins that we identified in extracts from colorectal carcinoma consisted of mutated variants of MUC5ac, A33 and CEAcam 5, 6. (12) Modifications in antigenic structure appeared to occur as mutations or post translational changes in the core peptide of those original glycoproteins found in the fetal state. The deviations in antigenic structure occurred in a unique way so that these tumor proteins appeared distinct and failed to react with the commercial antibodies that targeted the oncofetal proteins from which the TAA's were associated. Those antibodies derived from the original tumor membrane preparations were Neo 101 and its newer version Neo 102 targeting an altered molecule having some homologous sequences to MUC5ac, monoclonal $16 \mathrm{C} 3$ or Neo 201 which was derived from an altered form of CEAcam5, 6 and monoclonal 31.1 which targeted the posttranslational changes of A33. All of these monoclonals were effective in defining the presence of tumor protein by immunohistochemistry (IHC); however 31.1 antigen appeared heat labile and could only be identified on frozen section. The remaining two $\mathrm{mAbs}$ could target their protein in paraffin sections. As such, when employed in the OR for examining margins of resection in preparation for an anastomosis, kits in preparation containing the 3 monoclonals, will be used for the analysis of frozen section specimens.

\section{IHC Procedure on histologic specimens}

Specimens taken from margins are microtome sectioned and fixed in acetone for $20 \mathrm{sec}$ followed by PBS for 20 seconds. Slides are then pre- warmed on a slide dryer at $37^{\circ} \mathrm{C}$.

Pre-diluted antibody in PBS is then added to the slides for $3 \mathrm{~min}$. While incubating with $\mathrm{mAb}$, prepare $\mathrm{x} 2$ conc. DAB substrate solution. Using DAB plus kit (Invitrogen). Use one drop of solution \#1 and two 
drops of solution \#2 and \#3 per each $\mathrm{ml}$. of $\mathrm{H}_{2} \mathrm{O}$. Then shake of antibody mix and rinse in two beakers with $100 \mathrm{ml}$. PBS 5 sec $\times 2$ Add DAB substrate solution for 1.5 min. Rinse in PBS Dip once (5 sec.) in Gill \#2 hematoxylin solution. Wash briefly to develop blue color in $\mathrm{NH} 4 \mathrm{OH}(0.4 \%)$ in tap water. Put in $\mathrm{dH}_{2} \mathrm{O}$ and mount using a water based mounting solution followed by microscopic analysis. Procedure takes about $15 \mathrm{~min}$.

\section{Results}

We had originally demonstrated the presence of colon tumor antigen by (IHC) in all fully malignant bowel lesions that had been examined in our lab (Fig.3). By using these antibodies in examining post-operative colon cancer specimens, we unexpectedly noted that antigen expression was also present in normal appearing colonocytes adjacent to the primary malignancy. (see Fig. 2) This process appeared to represent premalignant transformation taking place in a field adjacent to the primary lesion.

When factors that could lead to the recurrence of tumor at the anastomotic site were first under consideration, we felt that that it might be of value to reexamine those margins of resection that were adjacent to the primary malignant lesion and were employed in the initial bowel anastomosis. Here routine histology of the tissue sampled indicated that the colonocytes adjacent to tumor were phenotypically normal in appearance. We examined 8 consecutive instances where bowel anastomosis resulted in re- growth of tumor in the suture line. Table 1 list the nature of the primary lesion having undergone resection, as well as which antigen was expressed within the tumor. The antigen in the anastomotic recurrence was then compared to that in the primary cancer as well as the altered colonocytes and found to be identical. In each of the 8 patients, tumor antigen was noted in the adjacent normal appearing colonocytes. Patterns of expression however, were scattered among the cells suggesting that antigen expression varied over time and that multiple samples had to be obtained for examination at surgery. We later examined 5 patients having undergone bowel resection, where no evidence of anastomotic recurrence had developed. In this small group, none of the mucosal cells were found to express tumor antigen. It was felt that if tumor had arisen as a result of a field effect, where multiple normal appearing cells might be in the process of transition, that the lesion being resected may have developed in the lower aspect of the field and that changes that existed in normal colonocytes may have extended only a few millimeters below the lesion, well within margins of resection that had been employed.

Colon samples were also examined from 50 patients having a bowel resection in the absence of malignant pathology. Specimens were examined by IHC employing those mAbs known to characterize the several colon cancer TAAs. In none of these normal colon specimens did any of the colonocytes demonstrate evidence of tumor antigen expression.

Table 1. examining the nature of antigen expression in specimens associated with anastomotic recurrence.

\begin{tabular}{|c|c|c|c|c|c|c|c|}
\hline Patient & Age/Sex & Tumor Location & Size & $\begin{array}{l}\text { TNM stage } \\
\text { Primary/Recurrence } \\
\text { Surgery Date } \\
\end{array}$ & $\begin{array}{l}\text { Tumor } \\
\text { margin } \\
\text { by H\&E }\end{array}$ & $\begin{array}{l}\text { Tumor } \\
\text { in margin }\end{array}$ & $\begin{array}{l}\text { Antigen } \\
\text { in recurrence' margin }\end{array}$ \\
\hline RS & $76 \mathrm{M}$ & $\begin{array}{l}\text { Sigmoid } \\
\text { Colon }\end{array}$ & $\begin{array}{l}3.5 \\
\mathrm{~cm}\end{array}$ & $\begin{array}{l}\text { T3N0M0 } \\
7 / 25 / 2005 \text { to } 5 / 20 / 2006\end{array}$ & $\mathrm{Neg}$ & $\begin{array}{l}\text { Neo } 102-25 \% \\
\text { Neo } 201-10 \% \\
\end{array}$ & $\begin{array}{l}\text { Neo102-25\% } \\
\text { Neo } 201-50 \% \\
\end{array}$ \\
\hline $\mathrm{HD}$ & $55 \mathrm{M}$ & Rt. Colon & $\mathrm{n} / \mathrm{a}$ & $\begin{array}{l}\text { T1N0M0 } \\
7 / 15 / 2005 \text { to } 3 / 31 / 2006\end{array}$ & Neg & $\begin{array}{l}\text { Neo 102-neg } \\
\text { Neo201-40\% }\end{array}$ & $\begin{array}{l}\text { Neo } 102-40 \% \\
\text { Neo } 201-50 \% \\
\end{array}$ \\
\hline JS & $71 \mathrm{~F}$ & Rt. Colon & $\begin{array}{l}2.7 \\
\mathrm{~cm}\end{array}$ & $\begin{array}{l}\text { T2N0M0 } \\
9 / 23 / 2008 \text { to } 12 / 15 / 2009\end{array}$ & Neg & ? 31.1 pos & ?31.1 \\
\hline JW & $77 \mathrm{M}$ & Rt. Colon & $5 \mathrm{~cm}$ & $\begin{array}{l}\text { T4N0M0 } \\
9 / 17 / 2009 \text { to } 7 / 26 / 2010\end{array}$ & Neg & $\begin{array}{l}\text { Neo } 102-10 \% \\
\text { Neo } 201-10 \%\end{array}$ & $\begin{array}{l}\text { Neo } 102-70 \% \\
\text { Neo } 102-10 \%\end{array}$ \\
\hline ES & $80 \mathrm{~F}$ & Rt. Colon & $5 \mathrm{~cm}$ & $\begin{array}{l}\text { T4N0M0 } \\
722 / / 2010 /\end{array}$ & Neg & $\begin{array}{l}\text { Neo } 102-5 \% \\
\text { Neo } 201-5 \%\end{array}$ & $\begin{array}{l}\text { Neo } 102-60 \% \\
\text { Neo } 201-40 \% \\
\end{array}$ \\
\hline VP & $77 \mathrm{~F}$ & Rt. Colon & $4 \mathrm{~cm}$ & T3N2M0 & $\mathrm{Neg}$ & $\begin{array}{l}\text { Neo } 102-5 \% \\
\text { Neo } 201-10 \%\end{array}$ & $\begin{array}{l}\text { Neo } 102-50 \% \\
\text { Neo } 201-50 \%\end{array}$ \\
\hline JG & $72 \mathrm{M}$ & $\begin{array}{l}\text { Sigmoid } \\
\text { Colon }\end{array}$ & $3 \mathrm{~cm}$ & T3N0M0 & Neg & $\begin{array}{l}\text { Neo } 102-5 \% \\
\text { Neo201-15\% }\end{array}$ & $\begin{array}{l}\text { Neo } 102-90 \% \\
\text { Neo } 201-20 \%\end{array}$ \\
\hline JK & $82 \mathrm{M}$ & $\begin{array}{l}\text { Lt. } \\
\text { Colon }\end{array}$ & $\begin{array}{l}3.5 \\
\mathrm{~cm}\end{array}$ & T3N0M0 & Neg & $31.1 ?$ & ?31.1 \\
\hline
\end{tabular}




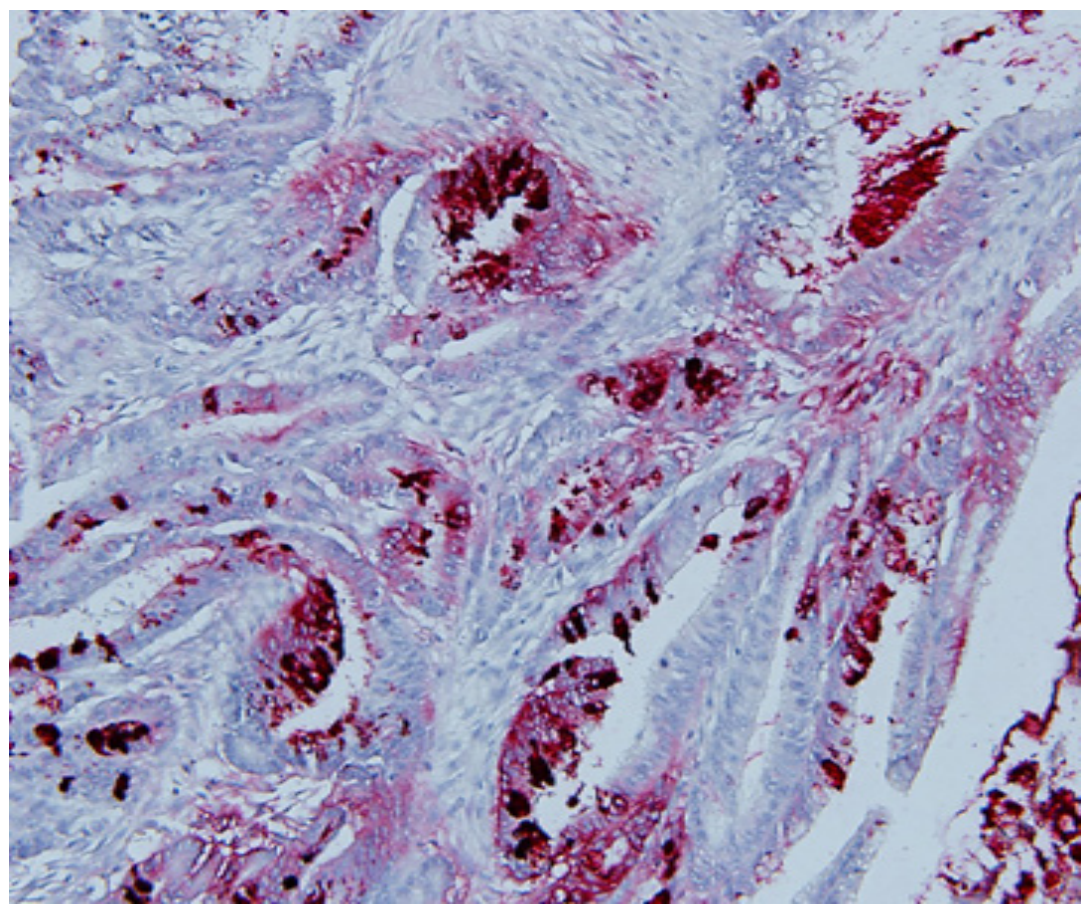

Figure 3. Carcinoma of the Colon expressing immunogenic Tumor Associated Antigen identified using Monoclonal antibody Neo 102.

\section{Discussion}

Many colorectal surgeons have considered re appearance of tumor in the suture line of the bowel to be related to the surgical technique employed during resection (13) as well as inadequate removal of the adjacent lymphatics from the tissue surrounding the primary lesion $(14,15$,) Others have speculated that exfoliated cells from the primary lesion have implanted in the bowel wall causing the recurrence. As such they have employed cytocidal agents applied to distal bowel ends, as a method for reducing the potential for local recurrence (16). Based on the premise of inadequate resection, most have felt that at the time of a low anterior resection, one should obtain distal clearance beyond the primary tumor of at least $5 \mathrm{~cm}$. This was considered to be an important requirement for minimizing the problem $(17,18)$. Later this concept was modified so that a surgical margin of $2 \mathrm{~cm}$. distal to the primary lesion was considered sufficient. Little of these approaches however, have altered the problem of a post-operative anastomotic recurrence. A more reasonable explanation relates to defining the presence of immunogenic tumor proteins expressed in normal appearing colonocytes adjacent to a primary malignant bowel lesion. This finding is now felt to be a factor for enhancing the potential for development of local recurrent disease, should those atypical colonocytes be included in the anastomotic field.

To better understand the nature and origin of transforming colonocytes in proximity to a primary colonic lesion, it now appears that a field effect may exist around the site of the primary malignancy (19). Such a field probably represents a site of oncogenic transformation wherein an array of transforming cells develops secondary to the effect of an oncogenic virus or carcinogen. In this field, the initial groups of cells that complete the transformation to a fully malignant phenotype probably suppress surrounding premalignant cells from further transformation on a local immunogenic basis. Removal of the primary lesion may eliminate this suppressive effect and allow premalignant cells i.e. colonocytes expressing antigen, to progress to the fully malignant phenotype, the anastomotic recurrence (20).

This phenomenon of a field effect with premalignant yet normal appearing cells adjacent to a malignancy has now been recognized with other lesions such as lung cancer. Kadara et. al. employed a genetic approach to examine normal cells adjacent to lung cancer to define premalignant changes taking place. Transforming cells that were identified were felt to define early premalignant changes (21). We are now in the process of mapping out the field effect surrounding colonic malignancies and evaluating genetic alterations in the transforming colonocytes.

\section{Conclusion}

At present, the standard for following patients undergoing anterior resection or any procedure where the margins of resection might be of concern, is the use of endoscopic ultrasound along with colon- 
oscopy (22). In the future, employing Immunohistochemical procedures in the OR at time of evaluation of margins of resection is expected to become a standard. We believe that this will eventually preempt the need for the colonoscopy/EUS which defines the lesion as it is developing, rather than preventing its occurrence.

\section{Competing Interests}

The authors have declared that no competing interest exists.

\section{References}

1. Meighly M.R.B., Hall C. Anastomotic Recurrence of Colorectal Cancer- A Biologic Phenomenon or an Avoidable Calamity. Gut. 1987; 28: 786-791

2. Morrison P.N., Corman M.L., Culler S.A., Vandenheimer M.C. Anastomotic Recurrence after Anterior Resection for Carcinoma. Dis. Colon \& Rectum. $1976 ; 19: 219-224$

3. Hojo K. Anastomotic Recurrence after Sphincter Saving Resection for Rectal Cancer. Dis. Colon \& Rectum. 1986; 29: 11-14

4. Piehl E., Hughs E.S.R., McDermott F.T., Price A.B. Recurrence of Carcinoma of the Colon and Rectum at the Anastomotic Suture line. Surg. Gyn and Obstet. 1981; 153: 495-496

5. Rosenberg H. The Etiology of Colonic Suture Line Recurrence. Ann. Royal College Surg, England. 1971; 61: 251-257

6. Arlen M., Saric O, Wang X., Dubeykonskiy A., Arlen P. Nannocytology vs Immunohistochemistry of Intestinal Colonocytes to Assess the risk of Colon Cancer Based on Field Cancerization. J. Cancer. 2013; 4: 165-169

7. Arlen M., Tsang K.Y.,Bartal A.,Wolf J., Saric O. Monoclonal Antibodies to Immunoreactive Tumor Associated Antigen (TAA) from Human Colon Carcinoma. J. Antibody Immunoconjugates and Radiopharmaceuticals, 1991; 4:895-905

8. Arlen M., Tsang K.Y. The Nature of the Monoclonal Antibodies Derived from Immunogenic Membrane Antigen of Human Colon Carcinoma Origin. J.Tumor Marker Oncology. 1990; 5:313-319

9. Arlen M., Arlen P., Bristol A., Wang X., Luka J, Gupta R., Saric O. The Use of Specific Monoclonal Antibodies to Target Immunogenic Tumor Proteins in Patients with Recurrent Pancreatic and Colrectal Cancer. Current Drug Delivery. 2012; 9: 52-56

10. Arlen M., Hollinshead A.C, Tsang K.Y. Identification and Characterization of a Colon TAA. Annals N.Y.Academy of Science. 1993

11. Arlen M., Tsang K.Y. Monoclonal Antibodies and their Role in Modulation of the Immume System. J.Surg Oncology 1993; 54:103-108

12. Arlen M., Arlen P., Coppa E, Crawford J., Wang X., Saric O., Dubokouvskiy A., and Molment E. Identification of the Oncofetal Tumor Antigens that Characterize Colorectal Carcinoma for use in Diagnosis and Therapy. J. Gastroent.Oncol 2014; In Press

13. Majima S, Takahashi T, Yokayama $Y$ and Mataushiga H. Studies on the Mechanism and Prevention of Local Recurence of Carcinoma of the Suture Line after Colonic Resection. Jap. J. Surgery. 1978 1:93-98

14. Lofgreen E.P, Wange J.M, Dokerty M.B. Local Recurrence of Carcinoma after Anterior Resection of the Rectum and Sigmoid: Relationship with length of normal mucosa excised distal to the Lesion. Arch. Surg. 1957; 74: 825-838

15. Furuhata T, Hata F., Kihara C., Okita K., et al. Anastomotic suture line recurrence of early rectal carcinomas that had been resected by laparoscopic surgery. Int. Surg.2007; 92: 262-265

16. Umpleby H.C, Williamson R.C.N. The Efficacy of Agents employed to Prevent Anastomotic Recurrence in Colorectal Carcinoma. Ann Royal College Surg. England. 1984; 27: 803-810

17. Williams N.S., Dixon M.F., Johnston D. Reappraisal of the $5 \mathrm{~cm}$ rule of distal excision for Carcinoma of the Rectum. A study of distal intramural spread and of patients survival. Br J Surg. 1983; 70: 150-154

18. Hellinger M.D., Santiago C.A. Reoperation for recurrent Colorectal Cancer. Clin.Colon rectal Surg. 2006; 19:228-236

19. Chai H., Brown R.E. Field Effect in Cancer-An Update. Ann Clin Lab Sci Autumn 2009; 39: 331-333

20. Motz G.T., Coukos G. Deciphering and Reversing Tumor Immune Suppression. Immunity. 2013; 39: 61-73

21 Kadara H., Fujimoto J., Yoo S., Maki Y., Gower A.C., Kabbout M, et al. Transcriptomic Architecture of the Adjacent Airway Field Cancerization in Non-Small Cell Lung Cancer. JNCI 2014; : 10.1093-1096

22. Nakajima S. The Efficacy of EUS for the Detection of Recurrent Disease in the Anastomosis of Colon. Diagnostic and Therapeutic Endoscopy 2001; 7:149-158. 